\title{
From the first human gene-editing to the birth of three-parent baby
}

\author{
Xiaoxue Zhang $^{1 *} \&$ Si Wang ${ }^{2 * *}$ \\ ${ }^{1}$ Higher Education Press, Beijing 100029, China; \\ ${ }^{2}$ National Laboratory of Biomacromolecules, CAS Center for Excellence in Biomacromolecules Institute of Biophysics, Chinese Academy of \\ Sciences, Beijing 100101, China
}

Received November 02, 2016; accepted November 16, 2016; published online November 29, 2016

Citation: Zhang, X., and Wang, S. (2016). From the first human gene-editing to the birth of three-parent baby. Sci China Life Sci 59, 1341-1342. doi: 10.1007/s11427-016-0358-3

Gene Editing refers to the process of making targeted modifications to the genome, such as the deletion, insertion or replacement of targeted DNA sequences (Pan et al., 2011). Gene editing technologies fundamentally improve our approaches to biological basic research, gene therapy, genetic improvement, etc. In the field of stem cells, gene editing can be used to modulate cell fate, such as generation of induced pluripotent stem cells (iPSCs) (Ding et al., 2015), cellular differentiation and transdifferentiation (Zhang et al., 2014). In gene therapy, gene editing can be used to correct disease mutations in patient-derived cells, which holds great promise to cure related diseases in the future (Liu et al., 2012; Liu et al., 2014).

In recent years, ZFN (zinc-finger nucleases) and TALEN (transcription activator-like effector nucleases) have become two representative site-specific nucleases for precise and efficient genome editing and show great potential in applications, while a third generation gene editing technology, the CRISPR/Cas9 system (clustered regularly interspaced short palindromic repeats/CRISPR-associated protein 9) triggered a revolution in genome editing (Cong et al., 2013; Mali et al., 2013). As a simple, fast and highly efficient approach, CRISPR/Cas9 has become a routine and indispensable tool for almost every biological or biomedical lab all over the world (Deng et al., 2015; Rong et al., 2014; Zhang and Zhou, 2014). CRISPR/Cas9 not only improves

*Corresponding author (email: zhangxx@hep.com.cn) **Corresponding author (email: si-violet@163.com) the speed and efficiency of gene editing, it also makes significant advances towards tasks that are hard or impossible to accomplish using previous approaches, such as production of transgenic pigs and non-human primates (Hai et al., 2014; Niu et al., 2014), and whole genome screening for functional genes relevant to cancer or other diseases as well as for genes involved in drug resistance (Shen and Ou, 2014; Zhou et al., 2014), etc. In May 2016, Gao et al. reported an archaebacterium-derived DNA nuclease named $\mathrm{NgAgo}$ that could edit mammalian genomic DNA in a more precise and efficient manner (Gao et al., 2016). Although there are still controversies about this approach, it shone a light for the next generation of gene-editing techniques.

In 2015, Dr. Junjiu Huang of Sun Yat-Sen University applied the CRISPR/Cas9 technology to take a lead in human embryo genome editing (Liang et al., 2015). In tripronuclear (3PN) zygotes (byproducts of assisted reproduction), Dr. Huang edited an $H B B$ gene that causes human $\beta$-thalassemia and sickle cell anemia, and found that CRISPR/Cas9 can correct $H B B$ gene mutations in some zygotes. This milestone work was published in Protein \& Cell and has attracted global attention across the whole field of life science.

Some scientists criticized this work on the basis that 'gene editing of human embryo is unethical-it can permanently modify human genes', which has led to a global debate on 'gene editing in human embryos' (Cyranoski, 2015; Cyranoski and Reardon, 2015; Zhang, 2015). The Washington Conference in December, 2015 also held a broad and 
in-depth discussion on the topic of gene editing in human embryos. The conference reached an agreement that preclinical research using human embryos, sperm cells and egg cells should not be paused or stopped, and that while genome editing in human embryos for basic research should be continued, it has to be in accordance with extensive ethical approval and within the constraints of related laws and regulations.

As early as February 2015, an overwhelming majority in the House of Commons of the United Kingdom had passed a resolution which allowed researchers to continue their research work on reproductive medical technologies of 'mitochondrial replacement therapy (MRT)', making UK the first country to legalize 'MRT'. Beyond this, on October 19, 2016 at the American Society for Reproductive Medicine Conference, a group led by Dr. Jin Zhang from the New Hope Fertility Center of America announced the birth of the world's first three-parent baby in April 2016.

Mutations in mitochondrial DNA (mtDNA) usually result in severe mitochondrial diseases. As mtDNA is inherited from oocytes, descendants of female carriers of mtDNA mutations usually have a very high frequency of developing mitochondrial diseases. 'MRT' is a type of assisted reproductive technology which replaces defective mitochondria in patients' oocytes with ones from healthy female donors' oocytes, while not changing the nuclear genomes of patients and their spouses. The resulting baby physiologically inherits genes from 'three parents' - two mothers and one father. Meanwhile, by gender selection of healthy embryos (only preserving male embryos), 'MRT' can prevent passing mitochondrial DNA-associated diseases to the next generation.

Although some scientists remain skeptical about the ethics and safety of this technology, it undoubtedly opens a new era of assisted reproductive medicine, and provides new perspectives and methods for the prevention of mitochondrial DNA-associated diseases. We will have to wait and see how future scientists further tackle problems in the basic science and clinical application of 'human embryo gene editing'.

Compliance and ethics The author(s) declare that they have no conflict of interest.

Cong, L., Ran, F.A., Cox, D., Lin, S., Barretto, R., Habib, N., Hsu, P.D., Wu, X., Jiang, W., Marraffini, L.A., and Zhang, F. (2013). Multiplex genome engineering using CRISPR/Cas systems. Science 339, 819-823.

Cyranoski, D. (2015). Ethics of embryo editing divides scientists. Nature $519,272$.

Cyranoski, D., and Reardon, S. (2015). Embryo editing sparks epic debate.
Nature 520, 593-594.

Deng, L., Ren, R., Wu, J., Suzuki, K., Izpisua Belmote, J.C., and Liu, G.H. (2015). CRISPR/Cas9 and TALE: beyond cut and paste. Protein Cell 6, $157-159$.

Ding, Z., Sui, L., Ren, R., Liu, Y., Xu, X., Fu, L., Bai, R., Yuan, T., Hao, Y., Zhang, W., Pan, H., Liu, W., Yu, H., Estaban, C.R., Yu, X., Yang, Z., Li, J., Wang, X., Izpisua Belmonte, J.C., Liu, G.H., Yi, F., Qu, J. (2015). A widely adaptable approach to generate integration-free iPSCs from non-invasively acquired human somatic cells. Protein Cell 6, 386-389.

Gao, F., Shen, X.Z., Jiang, F., Wu, Y., Han, C. (2016). DNA-guided genome editing using the Natronobacterium gregoryi Argonaute. Nat Biotechnol 34, 768-73.

Hai, T., Teng, F., Guo, R., Li, W., and Zhou, Q. (2014). One-step generation of knockout pigs by zygote injection of CRISPR/Cas system. Cell Res 24, 372-375.

Liang, P., Xu, Y., Zhang, X., Ding, C., Huang, R., Zhang, Z., Lv, J., Xie, X., Chen, Y., Li, Y., Sun, Y., Bai, Y., Songyang, Z., Ma, W., Zhou, C., Huang, J. (2015). CRISPR/Cas9-mediated gene editing in human tripronuclear zygotes. Protein Cell 6, 363-372.

Liu, G.H., Qu, J., Suzuki, K., Nivet, E., Li, M., Montserrat, N., Yi, F., Xu, X., Ruiz, S., Zhang, W., Wagner, U., Kim, A., Ren, B., Li, Y., Goebl, A., Kim, .J, Soligalla, R.D., Dubova, I., Thompson, J., Yates, J. 3rd, Esteban, C.R., Sancho-Martinez, I., Izpisua Belmonte, J.C. (2012). Progressive degeneration of human neural stem cells caused by pathogenic LRRK2. Nature 491, 603-607.

Liu, G.H., Suzuki, K., Li, M., Qu, J., Montserrat, N., Tarantino, C., Gu, Y., Yi, F., Xu, X., Zhang, W., Ruiz S., Plongthongkum, N., Zhang, K., Masuda, S., Nivet, E., Tsunekawa, Y., Soligalla, R.D., Goebl, A., Aizawa, E., Kim, N.Y., Kim, J., Dubova, I., Li, Y., Ren, R., Benne,r C., del So,1 A., Bueren, J., Trujillo, J.P., Surralles, J., Cappelli, E., Dufour, C., Esteban, C.R., Izpisua Belmonte, J.C. (2014). Modelling Fanconi anemia pathogenesis and therapeutics using integration-free patient-derived iPSCs. Nat Commun 5, 4330.

Mali, P., Yang, L., Esvelt, K.M., Aach, J., Guell, M., DiCarlo, J.E., Norville, J.E., and Church, G.M. (2013). RNA-guided human genome engineering via Cas9. Science 339, 823-826.

Niu, Y., Shen, B., Cui, Y., Chen, Y., Wang, J., Wang, L., Kang, Y., Zhao, X., Si, W., Li, W., Xiang, A.P., Zhou, J., Guo, X., Bi, Y., Si, C., Hu, B., Dong, G., Wang, H., Zhou, Z., Li, T., Tan, T., Pu, X., Wang, F., Ji, S., Zhou, Q., Huang, X., Ji, W., Sha, J. (2014). Generation of gene-modified cynomolgus monkey via Cas9/RNA-mediated gene targeting in one-cell embryos. Cell 156, 836-843.

Pan, H., Zhang, W., and Liu, G.H. (2011). Find and replace: editing human genome in pluripotent stem cells. Protein Cell 2, 950-956.

Rong, Z., Zhu, S., Xu, Y., and Fu, X. (2014). Homologous recombination in human embryonic stem cells using CRISPR/Cas9 nickase and a long DNA donor template. Protein Cell 5, 258-260.

Shen, Z., and Ou, G. (2014). CRISPR-Cas9 knockout screening for functional genomics. Sci China Life Sci 57, 733-734.

Zhang, K., Liu, G.H., Yi, F., Montserrat, N., Hishida, T., Esteban, C.R., and Izpisua Belmonte, J.C. (2014). Direct conversion of human fibroblasts into retinal pigment epithelium-like cells by defined factors. Protein Cell 5, 48-58.

Zhang, L., and Zhou, Q. (2014). CRISPR/Cas technology: a revolutionary approach for genome engineering. Sci China Life Sci 57, 639-640.

Zhang, X. (2015). Urgency to rein in the gene-editing technology. Protein Cell 6, 313 .

Zhou, Y., Zhu, S., Cai, C., Yuan, P., Li, C., Huang, Y., and Wei, W. (2014). High-throughput screening of a CRISPR/Cas9 library for functional genomics in human cells. Nature 509, 487-491.

Open Access This article is distributed under the terms of the Creative Commons Attribution License which permits any use, distribution, and reproduction in any medium, provided the original author(s) and source are credited. 